\title{
A PILOT STUDY FOR THE USE OF COUMARIN-480 TO ENHANCE THE FINGERMARKS
}

\author{
MUHAMMAD YASEEN ${ }^{\mathrm{a}, *}$, NOUMAN RASOOL ${ }^{\mathrm{b}}$, ZAHID FAROOQ $^{\mathrm{c}}$, \\ SHAHBAZ NAZIR ${ }^{\mathrm{d}}$, SHUMAILA CHOHAN ${ }^{\mathrm{e}}$
}

\begin{abstract}
A new alternative super glue post-treatment method for the enhancement of fingermarks over two different non-porous surfaces including glass slides and high density polyethylene (HDPE) sheets have been investigated. This is the first documented application of 2,3,6,7-tetrahydro-9methyl-1H,5H-quinolizino(9,1-gh)coumarin or coumarin-480 for the enhancement of cyanoacrylate fumed fingermarks. Coumarin-480 in ethanol was used as cyanoacrylate post-treatment dye. Fingermarks of seven different donors were aged for three different time periods (1 day, 1 week and 4 weeks) over non-fluorescent glass slides and HDPE sheets and developed with cyanoacrylate fumes. Upon staining with coumarin-480, fingermarks of varying qualities were observed under long UV radiations. Rhodamine 6G was used to assess the relative sensitivity of the coumarin-480 for the enhancement cyanoacrylate developed fingermarks. Pseudo-operational trials were conducted on glass bottles and high density polyethylene shopping bags. Coumarin-480 produced superior enhancement on HDPE shopping bags and glass bottles than the rhodamine $6 \mathrm{G}$.
\end{abstract}

Keywords: Fingermarks enhancement, Cyanoacrylate post treatment dye, Coumarin-480, Fluorescent dye

\section{INTRODUCTION}

One of the most valuable physical evidence found at almost every crime scene are latent fingermark [1]. A variety of techniques for the development and enhancement of latent fingermarks are reported in the

\footnotetext{
a Department of Chemistry, University of Education (Lahore), Faisalabad campus, Pakistan

${ }^{\mathrm{b}}$ Department of Biochemistry, University of Management and Technology, Lahore, Pakistan

${ }^{c}$ Department of Physics, University of Education (Lahore), Faisalabad campus, Pakistan

${ }^{d}$ Department of Education, Govt. of Punjab, Pakistan

e Institute of Chemistry, University of Punjab, Pakistan

*Corresponding author yaseen747pk@hotmail.com
} 
literature [2]. Cyanoacrylate or super glue fuming is an extremely efficient and simple method for the development of latent fingermarks. In the late 1970s, investigators in Japan and UK almost simultaneously discovered the abilities of cyanoacrylate to develop the latent fingermarks [3]. This method is based upon the inherent property of alkyl substituted cyanoacrylate esters to get polymerized over the fingerprint residue to produce visible three-dimensional fingermarks [4-6]. The exact chemical process of this technique is still under debate and is not well understood [7-9]. However, it is believed that anionic polymerization of alkyl cyanoacrylate is initiated by a variety of compounds like amino acids, fatty acids, and proteins present in the fingerprint residue. The main limitation of cyanoacrylate fuming is the whitish colour of the developed latent fingermarks which often lack the contrast with the light coloured substrates. To overcome such limitations, several super glue post-treatment methods have been developed [10-13]. These post-treatment methods range from dusting the cyanoacrylate fumed fingermarks with colour or fluorescent powders [14] or staining with a fluorescent dye solution like Ardox [13], basic yellow 40 and rhodamine 6G [15]. These fluorescent techniques provide a better contrast of the developed friction ridge impressions than the non-fluorescence techniques.

Many efforts have been made by the scientific community to explore the alternative fluorescent materials for the detection and enhancement of latent fingermarks [16-17]. Non-substituted coumarin (2-oxo-2H-chromene) exhibits very weak or zero fluorescence. However, its substituted derivatives exhibit intense fluorescence and are used in different branches of biology, physics, chemistry, and medicine [18]. For the first time in 1977, Dalrymple and co-workers reported the use of coumarin- 6 in conjunction with argon laser to develop the latent fingermarks [19]. Next year, Thornton reported a modified fingerprint powder by mixing coumarin- 6 with conventional black fingerprint powder [20]. In 1983, Kobus and co-workers investigated the application of coumarin-540 as super glue post-treatment dye [21]. The staining dye, coumarin-540, was none other than coumarin- 6 that had earlier been reported by Dalrymple [19]. High prices and the limited availability of forensic light sources and lasers in the early 1980s stimulated the scientific community to investigate alternative dyes and stains that can be excited by long wave ultra violet radiations [13]. Consequently, in 1992 Ardox was offered as an alternative to Rhodamine $6 \mathrm{G}$ that can be excited by using UV light [22]. It works well with laser and UV lamps. Ardox stained fingermarks fluoresce under $365 \mathrm{~nm}$ whereas better results could also be obtained under 450-480 nm excitation. Different, one step fluorescent cyanoacrylate products such as PolyCyano UV, Lumicyano and $\mathrm{CN}$-Yellow are now a days commercially available [23-25]. Hahn and Ramotowski has reported that the 
effectiveness of Polycyano UV is highly dependent on the surface itself in addition to the use of a modified fuming chamber to deliver the Polycyano UV powder into the glue dish [26].

Because of the availability of low-cost UV light sources than the expensive alternative light sources, there is still a large potential to explore alternative UV excited dyes that can stain the latent fingermarks either in one step or in two steps. However, the use of such dyes in conjunction with UV light requires special personal protective equipment to protect the skin and eyes. We decided to explore the use of coumarin-480 as a super glue post-treatment dye. The first part of this study aims to compare the sensitivity of coumarin-480 with rhodamine $6 \mathrm{G}$ for the enhancement of cyanoacrylate developed fingermarks over microscopic glass slides and HDPE sheets. The second part of this study consists of pseudo-operational trials that were conducted on two hundred shopping bags and two hundred glass bottles so as to establish whether the results obtained in the laboratory are reproducible or not.

\section{RESULTS AND DISCUSSION}

The preliminary task for this research work was to study the optical properties of coumarin-480 so as to determine the excitation wavelength and the type of barrier filters. The excitation wavelength was explored by measuring the UV-Visible spectrum in ethanol at room temperature. In ethanol, coumarin-480 exhibited two intense absorptions, one in shortwave UV region at $210 \mathrm{~nm}$ and the second in long wave UV region $390 \mathrm{~nm}$ in addition to a weak absorption at $258 \mathrm{~nm}$. Upon excitation at $390 \mathrm{~nm}, 10^{-4} \mathrm{M}$ solution of coumarin-480 in ethanol produced a broad emission band between 430-520 $\mathrm{nm}$ with emission maxima at $465 \mathrm{~nm}$ (Figure 1).

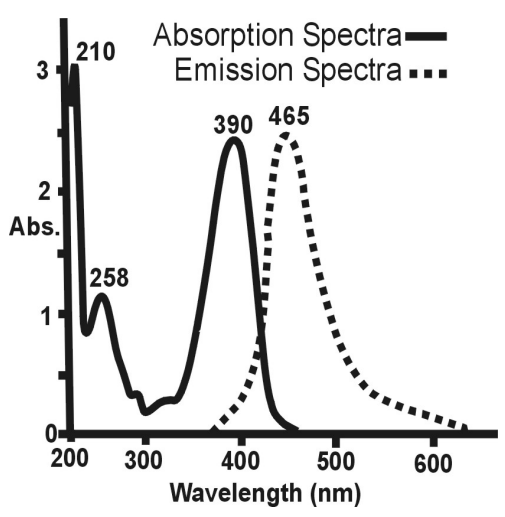

Figure 1. UV-Visible and emission spectra of coumarin-480 in ethanol 
Seven fingermark donors deposited thirty five split latent fingermarks (five depleted marks from each donor) over seventy microscopic glass slides according to the protocol as described above. Similarly, same fingermarks donors also deposited another set of thirty five split fingermarks (five depleted marks from each donor) over eighty HDPE sheets. After cyanoacrylate development, right half of every depleted fingermark was stained with coumarin-480 and the left half with rhodamine 6G solution. Negative controls (cyanoacrylate fumed fingermarks without any fluorescent stain) were run to check any inherent luminescence under wavelength of $390 \mathrm{~nm}$. Because of an intense absorption band exhibited by coumarin-480 at 390 $\mathrm{nm}$, this wavelength was explored to excite the coumarin-480 stained split fingermarks (right halves only). The images of fluorescent fingermarks were captured by using LP415 UV block filter having cut-on wavelength $415 \mathrm{~nm}$. Images of enhanced fingermarks were saved in tagged image file format (TIFF) without any processing (Figure 2).

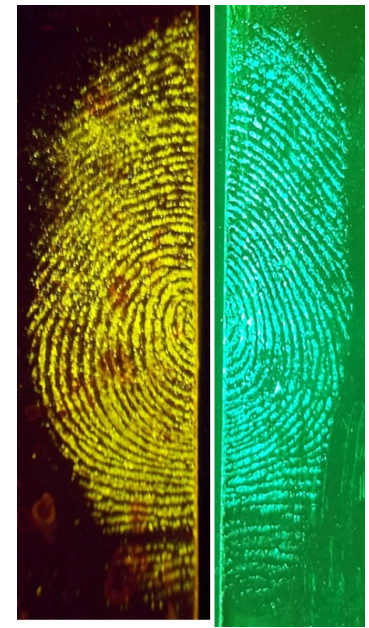

Figure 2. A split fingermark enhanced with coumarin-480 (right half) and rhodamine $6 \mathrm{G}$ (left half) on a glass slide

Each fingermark was given a comparative score (Table 1) based on the clarity of ridge details, contrast and background interferences [27]. The results of comparison between the performance of coumarin-480 and rhodamine $6 \mathrm{G}$ for the enhancement of one day old split fingermarks on microscopic glass slides and HDPE sheets are summarized below (Figure 3 ). 


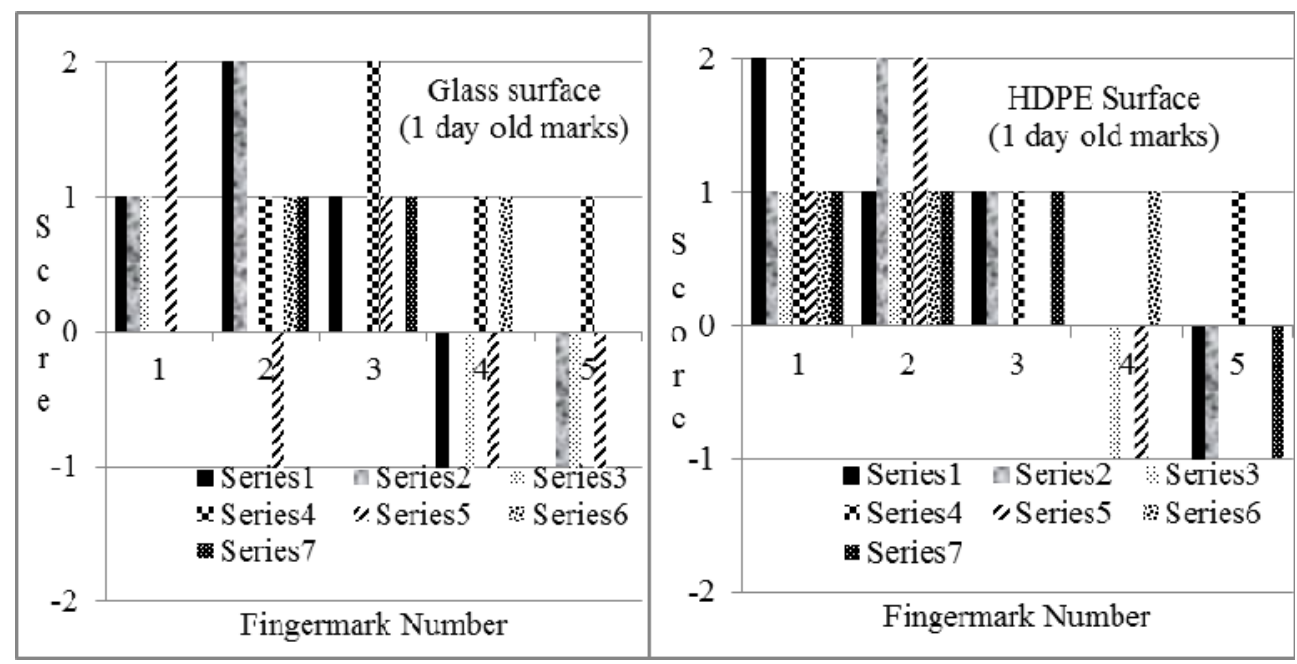

Figure 3. UC score of coumarin-480 enhanced one day old fingermarks on glass and HDPE surfaced

Although standard protocols were used to provide the degree of consistency and reproducibility between the fingermarks but because of many factors like emotional stress, the number of sweat pores, health, deposition time and pressure which are beyond the control of fingermark donor, natural variations among the developed fingermarks was observed. After direct comparison by using UC scale [27], coumarin-480 produced superior enhancement among $46 \%$ and $57 \%$ of one day old cyanoacrylate developed marks on glass and HDPE surfaces respectively than rhodamine 6G. UC score [27] for the enhancement of one and four week old cyanoacrylate developed marks on glass and HDPE surfaces with coumarin-480 are given below (Figure 4 and 5). 


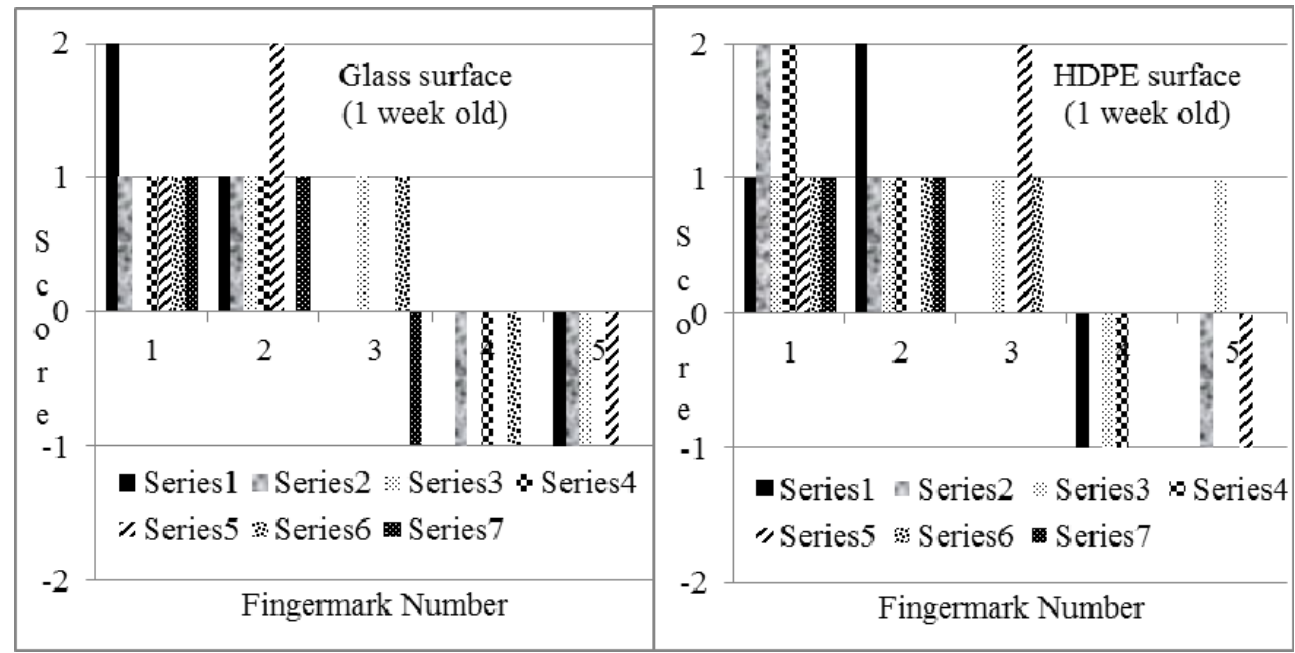

Figure 4. UC score of coumarin-480 enhanced one week old fingermarks on glass and HDPE surfaced

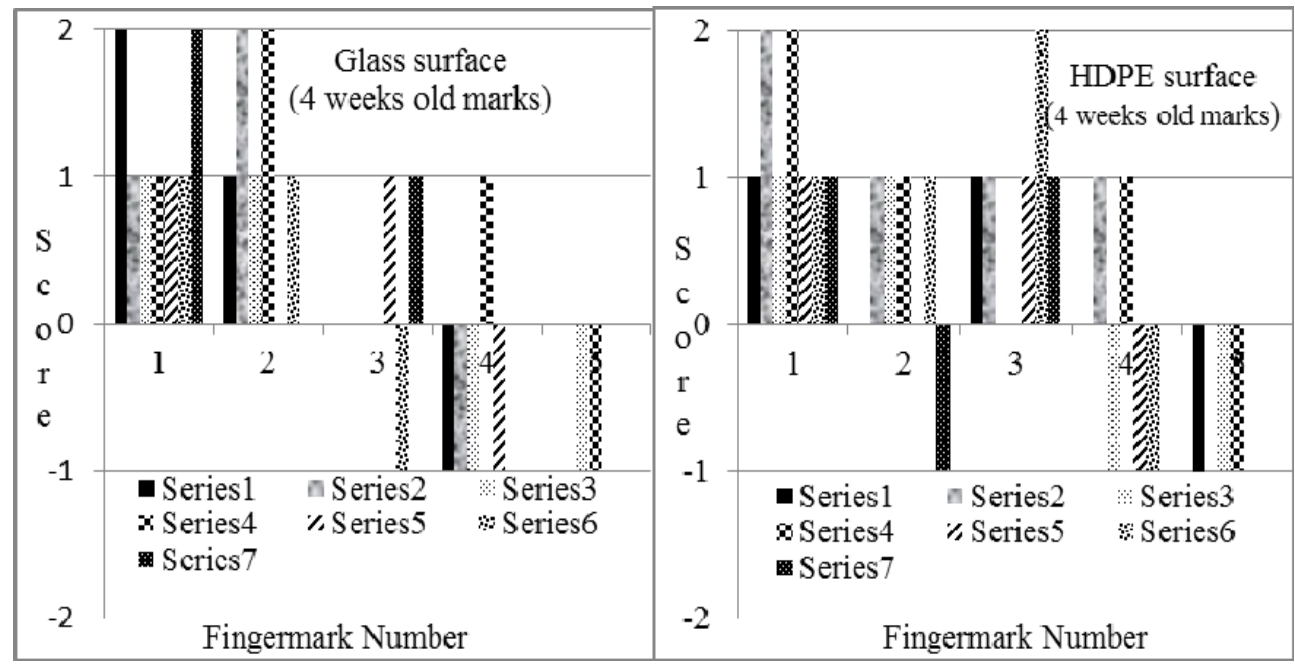

Figure 4. UC score of coumarin-480 enhanced four week old fingermarks on glass and HDPE surfaced 
Overall, coumarin-480 produced better enhancement than rhodamine $6 \mathrm{G}$ among $41 \%$ of cyanoacrylate developed fingermarks of three different ages on glass slides and $52 \%$ on HDPE surface. Coumarin- 480 failed to produce greater enhancement than rhodamine $6 \mathrm{G}$ among $20 \%$ of the marks on glass surface and $16 \%$ of the marks on HDPE surface. On both glass and HDPE surfaces, coumarin-480 was found to be superior super glue post treatment enhancement dye than rhodamine $6 \mathrm{G}$. Furthermore, the enhancement results were entirely dependent upon the amount of deposited cyanoacrylate polymer that is consistent with conventional cyanoacrylate stains.

Polythene shopping bags and glass bottles are often encountered in routine casework. Glass bottles and HDPE shopping bags were decided to be tested for pseudo-operational trials. All collected substrates were treated within two weeks of collection during which these were stored inside the laboratory at $25{ }^{\circ} \mathrm{C}$ and relative humidity around $55 \%$. Shopping bags were cut from the middle (vertically from top to bottom) and each piece after cyanoacrylate fuming was treated with a different enhancement technique. Similarly, glass bottles were randomly divided into two batches so that each batch consists of 100 glass bottles. All substrates were treated with cyanoacrylate fumes. Any mark with continuous ridge details and an area greater than $64 \mathrm{~mm}^{2}$ was counted [27-28]. Marks that showed signs of over fuming or overdevelopment were also noted. The total numbers of cyanoacrylate developed fingermarks detected under day light in each batch of shopping bags and glass bottles were counted. One batch of shopping bags and glass bottles was stained with coumarin-480 solution and the counter batched were stained with rhodamine $6 \mathrm{G}$. Figure 5 graphically illustrate the total number of fingermarks detected after cyanoacrylate fuming and subsequent enhancement with coumarin-480 and rhodamine $6 \mathrm{G}$ stains.

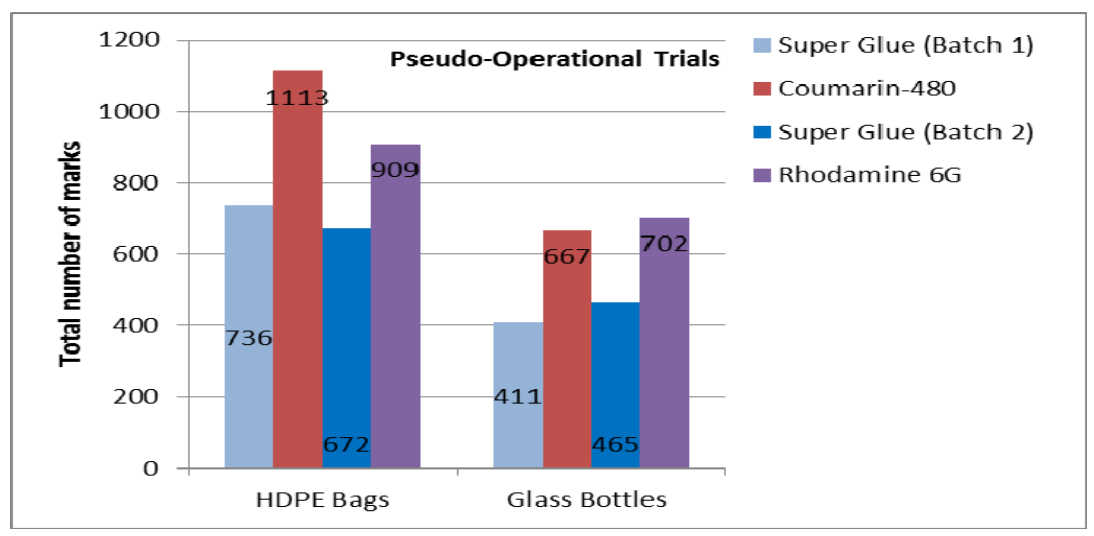

Figure 5. Pseudo-operational trials of coumarin-480 on shopping bags 


\section{CONCLUSIONS}

This study has revealed the potential of coumarin-480 as a superior super glue post treatment dye than the rhodamine $6 \mathrm{G}$ on HDPE and glass surfaces.

\section{EXPERIMENTAL SECTION}

Absorption and emission spectra of coumarin-480 were recorded in ethanol so as to determine its absorption and emission maxima which helped us to select appropriate excitation wavelength and the barrier filter. The UV-visible absorption spectrum of coumarin-480 was measured with Shimadzu UV-2450 spectrophotometer using a quartz cell of path length $1 \mathrm{~cm}$, whereas the emission spectrum was recorded with a commercial fluorimeter (Cary Eclipse from Varian).

Cyanobloom ${ }^{\mathrm{TM}}$ purchased from Foster and Freeman, the UK was used as a source of cyanoacrylate fumes. Laser-grade coumarin- 480 was obtained from Exciton, USA and was used as received. Cyanoacrylate fuming was performed in CyanoSafe ${ }^{\mathrm{TM}}$ filtered cyanoacrylate fuming chamber (Product No. CAS30, Sirchie, USA) having an internal volume of $0.43 \mathrm{~m}^{3}$ by using 2 grams of Cyanobloom ${ }^{\mathrm{TM}}$ as a source of cyanoacrylate fumes. Temperature and humidity of the cyanoacrylate chamber were maintained at $120{ }^{\circ} \mathrm{C}$ and at $80 \%$ respectively. After 45 minutes, all samples were removed from the chamber and stored at room temperature for the next 48 hours. Polilight ${ }^{\circledR}$ PL500 (Rofin, Australia Pty. Ltd.) was used as an excitation source.

Rhodamine $6 G$ was purchased from Sirchie, USA and was used as received. Solvent grade methanol, 2-propanol, methyl ethyl ketone and ethanol were purchased from Sigma Aldrich, USA and were used after distillation. The working solution of rhodamine $6 \mathrm{G}$ was prepared as used by the Australian Federal Police [29] by dissolving $0.2 \mathrm{~g}$ of rhodamine $6 \mathrm{G}$ in $200 \mathrm{ml}$ of isopropanol followed by the addition of $300 \mathrm{ml}$ of methyl ethyl ketone to obtain $500 \mathrm{ml}$ of stock solution. The $250 \mathrm{ml}$ of stock solution of rhodamine $6 \mathrm{G}$ was diluted with $750 \mathrm{ml}$ of water to obtain $1000 \mathrm{ml}$ of working solution of rhodamine $6 \mathrm{G}$.

For the optimization of coumarin-480, only charged fingermarks were used to ensure that sufficient cyanoacrylate was deposited. This involved donors rubbing fingers on their forehead, and then rubbing their hands together for homogenization prior to depositing fingermarks on the surface. Coumarin-480 was tested in a number of carrier solvents but the formulation that produced the best results was $0.25 \mathrm{~g}$ of dye dissolved in 
$1000 \mathrm{ml}$ of ethanol. The higher concentration caused sufficient background staining and the lower concentrations decreased the contrast of the developed marks. The optimal wavelength for the excitation of coumarin-480 was found to be $390 \mathrm{~nm}$ which is its absorption maximum.

In the first part of this pilot study, non-fluorescent plain microscopic glass slides (VWR, USA) and transparent HDPE sheets were used as substrates without any treatment. For pseudo-operational trials, one hundred HDPE shopping bags were collected from the dust bins and the old stationary store room of the campus whereas, two hundred glass empty bottles of different brands were collected from the dust bins and an abandon cafeteria.

In order to check the inter-variability of developed latent fingermarks four males and three females all having ages between 25-40 years were randomly selected from a pool of twenty people. They were asked not to apply any cosmetics on their bodies before coming to work. All fingermark donors deposited their natural fingermarks by pressing the volar pad of one finger at the junction of two microscopic slides and the other finger at the junction of two HDPE sheets for two seconds each. It left one-half fingermark on each substrate and allowed the two halves of the same fingermark to be processed separately by two different techniques. Before deposition of fingermarks on microscope slides and HDPE sheets all donors were directed to gently rub their fingers and palms on another in order to uniformly distribute the secretions.

The concept of depletion series was used to evaluate the enhancement of relatively weak developed cyanoacrylate fingermarks. A series of fingermarks were deposited by each donor by the successive pressing of the same finger against the same surface. By doing so, the quantity of fingermark residue decreases successively from first to the last fingermark. Before this study, seven selected fingermark donors were tested for natural marks by cyanoacrylate fuming followed by enhancement with rhodamine $6 \mathrm{G}$ to select the appropriate number of depletion marks over microscopic slides and HDPE sheets. Seven donors were ranked and assigned an alphabet on the basis of developed fingermarks. Alphabet "A" was assigned to an excellent judged natural fingermark donor whereas alphabet " $G$ " was assigned to the worst judged fingermark donor. For each donor, a depletion series till $20^{\text {th }}$ mark was obtained by following the same protocol as described earlier. It was observed that for two fingermark donors (the worst donors) no fingermarks were observed after the third and fourth mark. Since the quality of fingermark is dependent on many factors like health of donor, emotional stress, deposition pressure and time etc. So we selected not to go beyond the fifth depletion mark by acknowledging the problems of depletion discussed in another study [30]. Hence, three sets of 
fingermarks on microscopic glass slides and three sets of fingermarks on HDPE sheets (five depletion fingermarks from each donor) were prepared so that each set consist of thirty five depleted fingermarks. As recommended by Kent [31] three sets of fingermarks on glass slides and three on HDPE sheets were aged for three different time intervals (one day, one week and four weeks). During the aging period, all fingermarks were stored at room temperature $\left(25^{\circ} \mathrm{C}\right.$, relative humidity $\left.55 \%\right)$ inside the laboratory over a table.

Working solution of coumarin-480 and rhodamine $6 \mathrm{G}$ were applied to the right and left halves of each set of cyanoacrylate developed marks respectively by spraying with a squirt bottle. After 10 seconds, the excess of rhodamine $6 \mathrm{G}$ and coumarin-480 were removed by washing with distilled water. All substrates after washing were air dried under darkness.

The right halves of each set of coumarin-480 stained fingermarks $(35 \times 3 \times 2$ marks) were excited under $390 \mathrm{~nm}$ light which was accomplished by down tuning the $415 \mathrm{~nm}$ filter of Polilight ${ }^{\circledR}$ by selecting the $t 25$ position. The output power of Polilight ${ }^{\circledR}$ PL500 was maintained at P3. Clear splash goggles with UV filtration up to $400 \mathrm{~nm}$, (Item no. 1005-007, UVPS ${ }^{\circledR}$, Chicago, IL, USA) were used to locate the coumarin-480 stained fluorescent fingermarks. Coumarin-480 enhanced fingermarks were captured by using LP415 UV block filter (Midwest Optical Systems, Inc. USA; Cut-on wavelength 415 $\mathrm{nm}$ ) mounted in front of a 16-megapixel digital camera (Nikon L25). The left halves of each set of rhodamine $6 G$ stained fingermarks $(35 \times 3 \times 2$ marks) were excited under $505 \mathrm{~nm}$ and were photographed by using OG550 long pass barrier filter in front of a 16-megapixel digital camera (Nikon L25). All photos were captured under darkness within $1 \mathrm{~h}$ after the staining and drying. The angle of incident light (light guide) was maintained at approximately $45^{\circ}$ and the camera was held at the right angle.

The quality of enhanced fingermark images was visually assessed by one certified competent latent fingerprint examiner on a 15-inch monitor always under the same conditions of optical brightness. Enhanced fingermarks were numerically graded (Table 1) according to the published procedure [32-33]. It permits the pictorial appearance of enhanced latent fingermarks to be converted into a numerical value that can be used to compare the relative effectiveness of two development techniques.

Table 1. Fingermark grading system

\begin{tabular}{|c|c|}
\hline Score & Level of Detail \\
\hline+2 & Significant increase in enhancement when compared to rhodamine 6G \\
\hline+1 & Slight increase in enhancement when compared to rhodamine 6G \\
\hline 0 & No enhancement \\
\hline
\end{tabular}




\section{ACKNOWLEDGMENTS}

Authors are thankful to all the participants who voluntarily donated their fingermarks.

\section{REFERENCES}

1. C. Champod, C. Lennard, P. Margot, M. Stoilovic, Fingerprint and other ridge skin impressions, CRC Press, Boca Raton, USA, 2004.

2. H.C. Lee, R.E. Gaensslen, Advances in fingerprint technology, 2nd ed., CRC Press, Boca Raton, USA, 2001.

3. B. Yamashita, M. French, The fingerprint sourcebook, National Institute of Justice, 2011.

4. P. Casault, N. Gilbert, B. Daoust, Candian Society of Forensic Science Journal., 2017, 50, 1.

5. M. Tahtouh, S.A. Scott, J.R. Kalman, B.J. Reedy, Forensic Science International, 2011, 207, 223.

6. G. Groeneveld, S. Kuijer, Mde. Puit, Science \& Justice, 2014, 54, 42.

7. P. Czekanski, M. Fasola, J. Allison, Journal of Forensic Sciences, 2006, 51, 1323.

8. S.P. Wargacki, L.A. Lewis, M.D. Dadmun, Journal of Forensic Sciences, 2007, $52,1057$.

9. S.P. Wargacki, L.A Lewis, M.D. Dadmun, Journal of Forensic Sciences, 2008, 53, 1138.

10. B.K. Chesher, J.M. Stone, W.F. Rowe, Forensic Science International, 1992 , 57, 163.

11. D.A. Wilkinson, J.E. Watkin, Forensic Science International, 1993, 60, 67.

12. M. Takatsu, O. Shimoda, H. Teranishi, Journal of Forensic Sciences, 2012, $57,515$.

13. M.M. McCarthy, Journal of Forensic Identification, 1990, 40, 75.

14. L. Liu, Z. Zhang, L. Zhang, Y. Zhai, Forensic Science International, 2009, 183, 45.

15. W.D. Mazella, C.J. Lennard, Journal of Forensic Identification, 1995, 45, 5.

16. C. Xu, R. Zhou, W. He, L. Wu, P. Wu, X. Hou, Analytical Chemistry, 2014, 86, 3279.

17. H.L. Barros, V. Stefani, Forensic Science International, 2016, 263, 83.

18. B. Valeur, Molecular Fluorescence: Principles and Aplications, Wiley-Verlag Chemie GmbH.:Weinheim, Germany, 2001, 79.

19. B. Dalrymple, J.M. Duff, E.R. Menzel, Journal of Forensic Sciences, 1977, 22, 106.

20. J. Thornton, Journal of Forensic Sciences, 1978, 23, 536. 
21. H.J. Kobus, R.N. Warrener, M. Stoilovic, Forensic Science International, 1983, 23, 233.

22. J. F. Fallano, Journal of Forensic Identification, 1992, 42, 91.

23. S. Chadwick, L. Xiao, P. Maynard, C. Lennard, X. Spindler, C. Roux, Australian Journal of Foresic Sciences, 2014, 46, 471.

24. C. Prete, L. Galmichi, F-G. Quenum-Possy-Berry, C. Allain, N. Thiburce, T. Colard, Forensic Science International, 2013, 233, 104.

25. D.E. Weaver, E.J. Clary, Journal of Forensic Identification, 1993, 43, 481.

26. W. Hahn, R. Ramotowski, Journal of Forensic Identification, 2012, 62, 279.

27. V.G. Sears, S.M. Bleay, H.L. Bandey, V.J. Bowman, Science \& Justice, 2012, 52,145 .

28. R.P. Downham, S. Mehmet, V.G. Sears, Journal of Forensic Identification, 2012, 62, 661.

29. M. Stoilovic, C. Lennard, Fingermark Detection \& Enhancement, 4 ed., National Centre for Forensic Studies, Canberra, 2010.

30. S. Fieldhouse, Forensic Science International, 2011, 207, 96.

31. T. Kent, Journal of Forensic Identification, 2010, 60, 371.

32. C. McLaren, C. Lennard, M. Stoilovic, Journal of Forensic Identification, 2010, 60, 199.

33. International Fingerprint Research Group (IFRG) Guidelines for the Assessment of Fingermark Detection Techniques, Journal of Forensic Identification, 2014, 64, 174. 